\title{
Ring enhancing brain lesions in a patient with Acquired Immunodeficiency Syndrome (AIDS): a diagnostic dilemma
}

\author{
Simant Singh Thapa, ${ }_{1}^{1}$ Masood Pasha Syed, ${ }^{1}$ Aalok Khole ${ }^{2}$
}

${ }^{1}$ Department of Medicine, Saint Vincent Hospital at Worcester Medical Center, Worcester, Massachusetts, USA ${ }^{2}$ Infectious Disease, University of Massachusetts Medical School, Worcester, Massachusetts, USA

\section{Correspondence to}

Dr Simant Singh Thapa, thapasimant@gmail.com

Accepted 9 April 2019

\section{DESCRIPTION}

A 65 -year-old female former smoker with a medical history of HIV infection, cerebrovascular accident and hypertension presented with headache in the bilateral frontal and occipital region. Headache started 2 weeks ago, was moderate in intensity and dull in nature. She had associated nausea and vomiting with the occasional blurring of vision. On examination, her vital signs were normal. A funduscopic examination revealed benign fundi bilaterally. Cranial nerves were intact. Motor and sensory examinations were intact. Cerebellar signs were absent.

A CT scan of the head and an MRI brain showed ring-enhancing lesions in the left frontal lobe (figure 1A) and the right cerebellar lobe (figure 2A) with surrounding oedema and mass effect. Her toxoplasma IgG serology was positive, but IgM serology was negative. The HIV viral load was 3.5 million copies $/ \mathrm{ml}$, and CD4 count was 140 cell $/ \mathrm{mm}^{3}$. Due to elevated toxoplasma $\mathrm{IgG}$ level, low CD4 count and ring-enhancing brain lesions, she was empirically treated for toxoplasmosis with sulfadiazine, pyrimethamine and leucovorin.

Although a follow-up was scheduled in 2 weeks, the patient presented after 1 month with persistent headache, nausea and vomiting despite anti-toxoplasmosis therapy. Repeat MRI brain showed interval growth of the lesions in the left frontal lobe (figure 1B) and the right cerebellar lobe (figure 2B). The patient underwent craniotomy with the removal of posterior cerebellar mass as it was causing a posterior fossa mass effect. The biopsy was positive for primary adenocarcinoma of unknown origin.

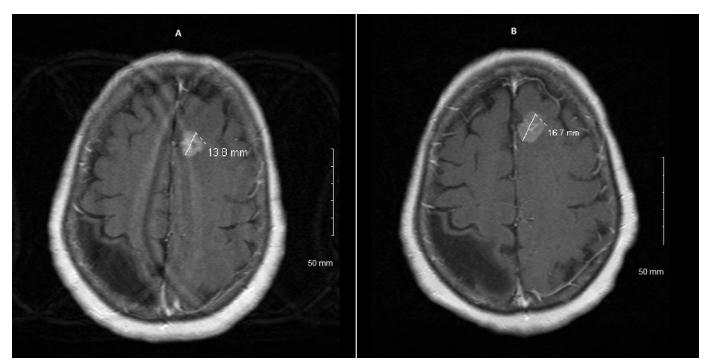

Limited 2019. No commercial re-use. See rights and permissions. Published by BMJ.

To cite: Thapa SS, Syed MP, Khole A. BMJ Case Rep 2019;12:e229686. doi:10.1136/bcr-2019229686
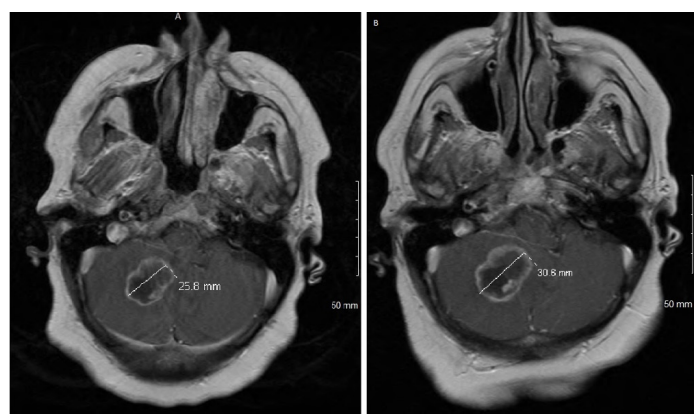

Figure 2 T1-weighted gadolinium enhanced axial views of MRI brain showing intervalincrease of the ringenhancing lesion in the cerebellum ( $A$ and $B$ ) in a span of 4 weeks' duration.

A recent mammogram and a colonoscopy were normal. A CT scan of the chest showed a $2.2 \mathrm{~cm}$ left upper lobe posterior irregular lung lesion highly suspicious for malignancy, particularly primary lung lesion, given metastatic intracranial adenocarcinoma (figure 3). CT abdomen and pelvis were normal. The initial plan was whole brain radiation and palliative chemotherapy, but the patient decided for hospice care and passed away in the subsequent 3 months.

Cerebral toxoplasmosis and primary central nervous system (CNS) lymphoma are the most common causes of ring-enhancing brain lesions in a patient with AIDS. Other conditions that may cause ring-enhancing brain lesions include primary CNS neoplasms, metastases, gliomas, neurocysticercosis, tuberculosis, granulomata, demyelination and abscesses. ${ }^{1}$ Lung cancer,

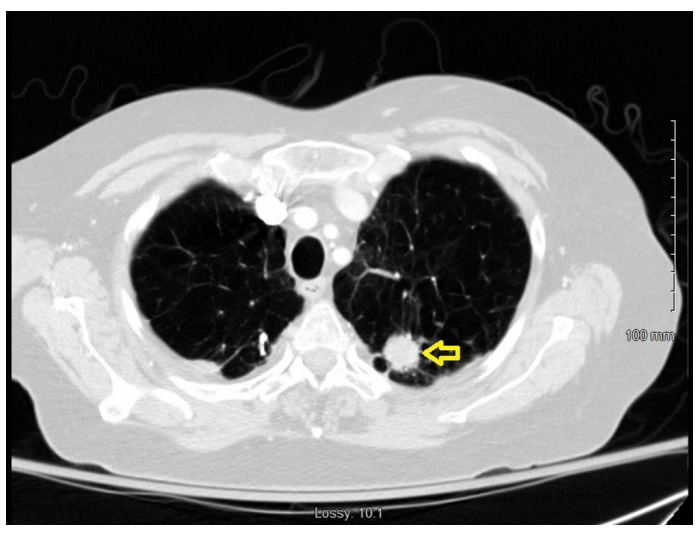

Figure 3 CT scan of chest showing a $2.2 \mathrm{~cm}$ left upper lobe posterior irregular lung lesion. 
breast cancer and melanoma account for the majority of patients with metastasis in the brain. ${ }^{1}$

The prevalence of toxoplasma $\operatorname{IgG}$ antibody seropositivity is $12.4 \%$ in the US population. ${ }^{2}$ Hence, a toxoplasma IgG is not necessarily that helpful to rule in CNS toxoplasmosis but instead helps to rule it out when negative. ${ }^{3}$ Although a brain biopsy is reserved for patients who fail to respond to empiric treatment of toxoplasmosis, an early brain biopsy should be strongly considered if results from imaging, serology or cerebrospinal fluid PCR studies are negative and/or suggest an aetiology different from toxoplasmosis. ${ }^{3}$ Cerebral toxoplasmosis has a predilection for the basal ganglia, and the CD4 count is usually less than 100 cells $/ \mathrm{mm}^{3}{ }^{3}$ Our patient had a cerebellar lesion, and the CD4 count was more than 100 cells/ $\mathrm{mm}^{3}$, which are not typical features of CNS toxoplasmosis. After

\section{Learning points}

- A ring-enhancing brain lesion in AIDS patients has a broad differential diagnosis-cerebral toxoplasmosis, primary central nervous system (CNS) lymphoma, gliomas, metastases, neurocysticercosis, tuberculosis, granulomata, demyelination and abscesses.

- An early brain biopsy should be considered for a definitive diagnosis of the ring-enhancing brain lesion especially in HIVAIDS patients who are refractory to initial empiric treatment for CNS toxoplasmosis.

- Proceeding directly for a brain biopsy for definitive diagnosis may also be considered if suspicion for CNS toxoplasmosis is low based on brain imaging, CD4 count and a negative serology. discussing with the patient, we decided to proceed with the empiric treatment first for CNS toxoplasmosis rather than brain biopsy directly, in order to avoid the possible risks associated with the brain biopsy. However, proceeding directly for brain biopsy for a definitive diagnosis should also be examined versus empiric treatment for cerebral toxoplasmosis in similar clinical scenarios. An early biopsy may be especially beneficial in toxoplasma seronegative patients as there is a small survival advantage for early versus delayed diagnosis of lymphoma and other malignancies. ${ }^{4}$

Contributors SST was primarily involved in writing, editing and critical review. MPS was involved in writing, editing and critical review. AK was involved in editing and critical review.

Funding The authors have not declared a specific grant for this research from any funding agency in the public, commercial or not-for-profit sectors.

Competing interests None declared.

Patient consent for publication Not required.

Provenance and peer review Not commissioned; externally peer reviewed.

\section{REFERENCES}

1 Garg RK, Sinha MK. Multiple ring-enhancing lesions of the brain. J Postgrad Med 2010:56:307-16.

2 Jones JL, Kruszon-Moran D, Rivera HN, et al. Toxoplasma gondii seroprevalence in the United States 2009-2010 and comparison with the past two decades. Am J Trop Med Hyg 2014;90:1135-9.

3 Panel on Opportunistic Infections in HIV-Infected Adults and Adolescents. Guidelines for the prevention and treatment of opportunistic infections in HIV-infected adults and adolescents: recommendations from the Centers for Disease Control and Prevention, the National Institutes of Health, and the HIV Medicine Association of the Infectious Diseases Society of America. 2018;2:C1. Available at http://aidsinfo.nih.gov/ contentfiles/lvguidelines/adult_oi.pdf.

4 Mathews C, Barba D, Fullerton SC. Early biopsy versus empiric treatment with delayed biopsy of non-responders in suspected HIV-associated cerebral toxoplasmosis: a decision analysis. AIDS 1995;9:1243-50.

Copyright 2019 BMJ Publishing Group. All rights reserved. For permission to reuse any of this content visit

https://www.bmj.com/company/products-services/rights-and-licensing/permissions/

BMJ Case Report Fellows may re-use this article for personal use and teaching without any further permission.

Become a Fellow of BMJ Case Reports today and you can:

- Submit as many cases as you like

- Enjoy fast sympathetic peer review and rapid publication of accepted articles

- Access all the published articles

- Re-use any of the published material for personal use and teaching without further permission

For information on Institutional Fellowships contact consortiasales@bmjgroup.com

Visit casereports.bmj.com for more articles like this and to become a Fellow 